Research

\title{
Dietary intake, lung function and airway inflammation in Mexico City school children exposed to air pollutants
} Isabelle Romieu*1, Albino Barraza-Villarreal ${ }^{1}$, Consuelo Escamilla-Núñez ${ }^{1}$, Jose L Texcalac-Sangrador ${ }^{1}$, Leticia Hernandez-Cadena ${ }^{1}$, David DíazSánchez ${ }^{2}$, Jordi De Batlle ${ }^{3,4}$ and Blanca E Del Rio-Navarro ${ }^{5}$

Address: ${ }^{1}$ Instituto Nacional de Salud Pública, Cuernavaca, Mexico, ${ }^{2}$ Human Studies Division, United States Environmental Protection Agency, Chapel Hill, North Carolina, USA, ${ }^{3}$ Centre for Research in Environmental Epidemiology (CREAL), Barcelona, Spain, ${ }^{4}$ CIBER Epidemiología y Salud Pública (CIBERESP), Barcelona, Spain and ${ }^{5}$ Hospital Infantil de México Federico Gómez, Mexico, DF, Mexico

Email: Isabelle Romieu* - iromieu@correo.insp.mx; Albino Barraza-Villarreal - abarraza@correo.insp.mx; Consuelo EscamillaNúñez - consueloescamilla@yahoo.com.mx; Jose L Texcalac-Sangrador - jtexcalac@gmail.com; Leticia Hernandez-

Cadena - lhcadena@correo.insp.mx; David Díaz-Sánchez - diaz-sanchez.david@epamail.epa.gov; Jordi De Batlle - jdebatlle@creal.cat; Blanca E Del Rio-Navarro - blancadelrio@yahoo.com.mx

* Corresponding author

Published: 10 December 2009

Respiratory Research 2009, 10:122 doi:10.1 186/1465-9921-10-122
Received: 25 May 2009

Accepted: 10 December 2009

This article is available from: http://respiratory-research.com/content//0/1//22

(c) 2009 Romieu et al; licensee BioMed Central Ltd.

This is an Open Access article distributed under the terms of the Creative Commons Attribution License (http://creativecommons.org/licenses/by/2.0), which permits unrestricted use, distribution, and reproduction in any medium, provided the original work is properly cited.

\begin{abstract}
Introduction: Air pollutant exposure has been associated with an increase in inflammatory markers and a decline in lung function in asthmatic children. Several studies suggest that dietary intake of fruits and vegetables might modify the adverse effect of air pollutants.

Methods: A total of 158 asthmatic children recruited at the Children's Hospital of Mexico and 50 non-asthmatic children were followed for 22 weeks. Pulmonary function was measured and nasal lavage collected and analyzed every 2 weeks. Dietary intake was evaluated using a 108-item food frequency questionnaire and a fruit and vegetable index ( $\mathrm{FVI}$ ) and a Mediterranean diet index (MDI) were constructed. The impact of these indices on lung function and interleukin-8 (IL-8) and their interaction with air pollutants were determined using mixed regression models with random intercept and random slope.
\end{abstract}

Results: FVI was inversely related to IL-8 levels in nasal lavage $(\mathrm{p}<0.02)$ with a significant inverse trend (test for trend $p<0.001$ ), MDI was positively related to lung function $(p<0.05)$, and children in the highest category of MDI had a higher FEV (test for trend $\mathrm{p}<0.12$ ) and FVC (test for trend $\mathrm{P}<0.06$ ) than children in the lowest category. A significant interaction was observed between FVI and ozone for FEV and FVC as was with MDI and ozone for FVC. No effect of diet was observed among healthy children.

Conclusion: Our results suggest that fruit and vegetable intake and close adherence to the Mediterranean diet have a beneficial effect on inflammatory response and lung function in asthmatic children living in Mexico City. 


\section{Introduction}

Exposure to air pollution has been associated with decrements in lung function [1-3] and an increase in respiratory symptoms [4], effects to which asthmatic children appear more susceptible $[5,6]$. We have recently shown that exposure to fine particles $\left(\mathrm{PM}_{2.5}\right)$ and ozone $\left(\mathrm{O}_{3}\right)$ results in acute airway inflammation and a decrease in lung function in both asthmatic and non-asthmatic children [7]. In a randomized controlled trial among asthmatic children, we also showed that antioxidant supplementation (vitamin $\mathrm{C}$ and $\mathrm{E}$ ) modulates the adverse effect of $\mathrm{O}_{3}$ on lung function and inflammatory response [8]. Fruits and vegetables are rich in antioxidants, in particular vitamin $\mathrm{C}$ and carotenoids, and higher intake has been related to better lung function in both adults [9] and children [10]. The Mediterranean diet has been shown to have a high antioxidant potential [11] and a beneficial effect on the risk of rhinitis [12] and asthma [13] in children and on lung function in adults[9]. In this study, we evaluated the impact and the potential modulating effect of dietary intake on lung function and airway inflammation among Mexico City school children exposed to high levels of air pollutants.

\section{Materials and methods Study design}

A dynamic panel (cohort) study of 6 to 14 year-old asthmatic and non-asthmatic school children living in Mexico City was conducted between June 2003 and June 2005. The asthmatic children $(n=158)$ were patients of the Federico Gomez Hospital Infantil de Mexico. The severity of diagnosis of their asthma was based on clinical symptoms and response to treatment and rated by a pediatric allergist as mild (intermittent or persistent), moderate or severe according to Global Initiative for Asthma (GINA) guidelines [14]. Fifty non-asthmatic children were recruited by asking the asthmatic children to invite a schoolmate or a friend from their neighborhood; dropped out early after recruitment $(9 \%)$. The children were enrolled during the first 10 months of the study (June 2003 - April 2004) and followed for an average of 22 weeks. Spirometric tests, measurements of interleukin- 8 (IL-8) levels in nasal lavage and anthropometry measurements were conducted every 2 weeks during follow-up. The study methodology has been described elsewhere [7].

All procedures were explained to the parents, who signed an informed consent form. The children also gave their informed consent. The study protocol was reviewed and approved by the ethics committees at both the National Institute of Public Health and the Hospital Infantil de Mexico.

We collected data on sociodemographic variables including mother and father education, the type of school attended by the child, past health history and potential indoor environmental exposures. Allergy test results and information on medication and medical visits over the previous 2 years were obtained from the medical record.

\section{Spirometry}

The spirometric tests were performed according to American Thoracic Society (ATS) specifications [15] using an EasyOne spirometer providing age, gender and height standardized pulmonary functions (ndd Medical Technologies, Andover, MA, USA). All lung function tests were performed by the same technicians, and the best of three technically acceptable tests was selected. Prior to the spirometric test, children answered a questionnaire on respiratory symptoms and had a clinical exam. If a child was diagnosed with respiratory infections, the spirometry was not done that day and was rescheduled for another day.

\section{Nasal lavage}

Nasal lavage was performed following the methodology proposed by Diaz-Sanchez et al. [16], with the children sitting with the nasopharynx closed while tilting their neck back 45 from vertical. Five $\mathrm{ml}$ of warm $\left(37^{\circ} \mathrm{C}\right)$ normal saline is instilled into each nostril by pipette. After 10 seconds, during which the subject shakes their head softly from side to side, they bring their head forward, expelling the wash fluid into a plastic receptable. The subject then performs up to four further nasal washes at 30-second intervals, with each wash being collected in a separate tube. We measured different cytokines including IL8, interferon gamma, IL6 and IL10 levels in nasal lavage in the laboratory of Dr. Diaz-Sanchez, using commercially available Elisa kits according to the manufacturer's instructions. However, except for IL8, the levels in most of the samples were under the detection limit and we report only the IL8 results. For logistic reasons, we did not determine cellular composition.

\section{Exhaled Nitric Oxide Levels}

The levels of FeNO were measured following the ATS guidelines [17] during outpatient visits to a clinic. Children were seated for at least 5 min before commencing the measurement and throughout the procedure; all measurements were conducted indoors to minimize external inhaled NO-free external air. NO was measured by chemiluminescence, using a continuous analyzer (CDL $88 \mathrm{sq}$ Michigan, USA). The FeNO reading was displayed in the monitoring system and the mean of the three acceptable tests was taken.

\section{Exhaled Breath Condensate Collection}

EBC was collected using an R-tube and the breath was cooled by placing an aluminum cooling sleeve over the disposable polypropylene tube [18]. Samples were 
obtained following the ATS/ERS Task Force recommendations $[18,19]$. Participants were asked to breathe tidally through the mouthpiece connected to the R-tube for 10 minutes to collect approx. $2 \mathrm{ml}$ of exhaled breath fluid, which was aliquoted and frozen to $-70 \mathrm{C}$ within $15 \mathrm{~min}-$ utes of collection.

\section{Dietary assessment}

At baseline, the mothers completed a 108-item food frequency questionnaire. A commonly used unit or portion size was specified for each food item (slice, glass, or natural unit such as one apple) and each mother was asked how often, on average, her child had consumed that amount over the previous year. Eight possible responses were given: 4 or more times per day; $2-3$ times per day; once per day; 5-6 times per week; 2-4 times per week; once per week; 1-3 times per month, and; never or less than once per month [20]. We assigned proportional weight to each frequency of consumption in order to obtain a daily intake for all items provided in the food frequency questionnaire. The following weights were assigned: never or less than once per month $=0,1-3$ times per month $=2 / 30$, once per week $=1 / 7,2-4$ times per week $=3 / 7,5-6$ times per week $=5.5 / 7$, once per day $=1,2-3$ times per day $=2.5$ and 4 or more times per day $=4$.

The questionnaire was adapted to the Mexican population from the one developed by Willett et al. and validated in this population [20-22]. This dietary information was used to calculate the daily consumption of 8 food groups: fruits, vegetables, cereals, legumes, dairy products, meat, fish and junk food.

From these groups, two food consumption indices were constructed: a fruit and vegetable index (FVI) and a Mediterranean diet index (MDI). 1) The FVI was based on the intake of fruits and vegetables and the consumption of vitamins or supplements reported on the questionnaire and were scored on a scale of 0 to 3 . Children whose consumption was below the median value were assigned 0 , while children whose consumption was at or above of the median value were assigned 1 . Additionally, the score was increased by 1 if the child reported consumption of vitamin $\mathrm{C}$ or supplement. This index was used as a continuous variable and a categorical variable considering 4 groups $(0,1,2,3) .2)$ The MDI was adapted from that designed by Trichopoulou [23] and was generated from the sum of the 8 food groups to evaluate adherence to the Mediterranean dietary pattern. This index was generated as follows: i) The moderate alcohol consumptions component was suppressed as it was not applicable to children: ii) The high monounsaturated/saturated consumptions were eliminated because fat ratio component as it could not be computed from the available data: iii) And a junk food component was introduced as a pre- vious study had suggested including fast food, snacks and sweets in Mediterranean diet scores [24]. In the case of fruits, vegetables, cereals, legumes, dairy products and fish, a value of 1 was assigned if consumption was above of the median value and 0 otherwise. For meat and junk food, the scoring was reversed. The scores for each food group were then summed to obtain a total score ranging from 1 (minimum adherence) to 4 (maximum adherence). This score was used a continuous variable and a categorical variable regrouping the score in four categories (category $1=$ score 1 to 3 , category $2=$ score 2 , category 3 $=$ score 3 , category $4=$ score 6 to 8 ).

\section{Air pollutant exposure assessment}

Exposure was estimated from the concentrations of outdoor fine particles $\left(\mathrm{PM}_{2.5}\right)$, nitrogen dioxide $\left(\mathrm{NO}_{2}\right)$ and ozone $\left(\mathrm{O}_{3}\right)$ recorded by the Mexico City government at four fixed-site central monitoring (RAMA) locations in the study area. Daily average, maximum moving average and 8-hour maximum concentrations and meteorological data (temperature and humidity) were obtained for all 505 days of the study period. The home of each child was geo-referenced using a geographic information system and the closest monitoring station was assigned to the child. All children attended public schools located close to their home and no fixed-site monitoring station was more than $5 \mathrm{~km}$ from a child's home or school.

\section{Statistical analysis}

The basic characteristics of the two groups of children were compared by bivariate analysis using the t-test, the Fisher exact test or the $\chi^{2}$ test, depending on variable type. The associations between diet indices and health outcomes were evaluated using linear mixed effects models with random intercept, considering models for continuous response. These models account for repeated measurements in the same individuals enabled us to appreciate the variability within and between subjects.

The model is as follows:

$$
Y_{i}=X_{i} \beta+Z_{i} b_{i}+\varepsilon_{i}
$$

Where; $i$ : represents the observation in the subject $i . Y_{j}$ corresponds to the dependent variables, $\mathrm{X}_{\mathrm{i}}$ are the independent variables with fixed effects and $\varepsilon_{\mathrm{i}}$ vector of residual components. A further advantage of the models used is that they do not discard subjects with incomplete data and take into account the correlation among repeated measurements in the same individual. The goodness of fit of each model was determined using residual diagnosis and the Hausman specification test [25]. Data on $\mathrm{O}_{3}$, $\mathrm{PM}_{2.5}$ and $\mathrm{NO}_{2}$ was included in our regression models on the basis of a previous analysis of these pollutants [7], which are known to affect pulmonary function and 
inflammatory markers. Models were adjusted for potential confounding, including gender, body mass index, previous day minimum temperature, corticoid use and chronological time. Other variables such as age, socioeconomic index (based on maternal education and school type), outdoor activities, atopic status, exposure to environmental tobacco smoke, use of anti-allergy medicine and season were not significant $(\mathrm{p}>0.10)$ and did not alter the results by $>1 \%$. We also tested for interaction between air pollutant exposure and dietary intake to assess any modifying effect of diet on the adverse effect of air pollution on lung health including interaction term in our models and also evaluating the effect of our nutritional indices in children exposed to low and high levels of pollutants. We calculated the percent of change in IL-8 and pulmonary function in relation with FVI and MDI using the coefficients from our regression models divided by the corresponding baseline characteristics. Analyses were conducted using STATA 9.2 (Stata Corp., College Station, Tx, USA).

\section{Results}

Table 1 presents the characteristics of the study population. The median age of participants was 9.6 years (Q25:7.9, Q75:11.0) for the asthmatic children and 9.3
(Q25:7.9, Q75:11.5) for the non-asthmatic children. Fifty-five percent of the asthmatic children were classified as having mild intermittent, $26.9 \%$ as having mild persistent and $17.5 \%$ as having moderate persistent asthma according to GINA guidelines. Eighty-nine percent of the asthmatic children and $72 \%$ of the non-asthmatic children had positive skin prick tests. The most common allergens sensitivities appear in the table 1.

\section{Dietary intake}

Table 2 presents the daily dietary intake of the children by food group and frequencies. There was no significant difference between the asthmatic and the nonasthmatic children. We observed a high frequency of intake of fruit or fruit juices, vegetables and dairy products as well as junk food. The most frequently consumed fruits were oranges, mandarins, apples, grapes, mangoes and grapefruits. Sixty nine percent of the asthmatic children and $70.9 \%$ of the non-asthmatic children were reported as consuming two or more vegetables per day. The most frequently consumed vegetables were tomatoes, zucchinis and chili peppers. The intake of junk food was also high in both groups, while the intake of fish was low. A total of $64.8 \%$ of the asthmatic children and $76.4 \%$ of the non-asthmatic children were reported as consuming two or more junk

Table I: Baseline characteristics of the study population: 158 asthmatic and 50 non-asthmatic children living in Mexico City, 2003-2005

\begin{tabular}{|c|c|c|c|c|}
\hline \multirow[b]{2}{*}{ Characteristics } & \multicolumn{2}{|c|}{ Asthmatic $(n=158)$} & \multicolumn{2}{|c|}{ Non-asthmatic $(n=50)$} \\
\hline & \multicolumn{2}{|c|}{ Median§ (Q25, Q75) } & \multicolumn{2}{|c|}{ Median (Q25, Q75) } \\
\hline Sex, \% masculine & 61.9 & & 40.0 & \\
\hline Age, years & 9.6 & $(7.9,11.0)$ & 9.3 & $(7.9,11.5)$ \\
\hline Weight, kg & 36.0 & $(27.0,46.0)$ & 32.0 & $(26.0,45.0)$ \\
\hline Height, cm & 137.0 & $(124.5,147.0)$ & 134.0 & $(127.0,147.0)$ \\
\hline $\mathrm{BMI}, \mathrm{Kg} / \mathrm{m}^{2}$ & 18.9 & $(16.3,22.0)$ & 18.1 & $(15.7,21.5)$ \\
\hline Maternal education, years (mean (SD)) & 9.8 & $(3.0)$ & 9.3 & (3.0) \\
\hline \multicolumn{5}{|l|}{ Smoking at home, \% } \\
\hline Father & 54.8 & & 45.0 & \\
\hline Mother & 41.1 & & 28.6 & \\
\hline Other person & 23.4 & & 29.1 & \\
\hline Allergy prink test positive (Atopics) (\%) & 88.8 & & 80.0 & \\
\hline \multicolumn{5}{|l|}{ Main allergens testing (\%) } \\
\hline Cat & 28.1 & & 27.3 & \\
\hline Dog & 20.0 & & 21.8 & \\
\hline House dust mite & 61.9 & & 45.4 & \\
\hline Cockroach & 41.9 & & 30.9 & \\
\hline \multicolumn{5}{|l|}{ Asthma diagnosis, \% } \\
\hline Moderate persistent & 17.5 & & & \\
\hline Mild persistent & 26.9 & & & \\
\hline Mild intermittent & 55.0 & & & \\
\hline \multicolumn{5}{|l|}{ Baseline lung function and IL-8 levels } \\
\hline $\mathrm{FEV}_{1}, \mathrm{~L}($ mean $(\mathrm{SD}))$ & 1.9 & $(0.7)$ & 1.95 & $(0.6)$ \\
\hline FVC, L (mean (SD)) & 2.3 & $(0.8)$ & 2.25 & $(0.7)$ \\
\hline $\mathrm{IL}-8, \mathrm{pg} / \mathrm{m} / \S$ & 157.2 & $(78.2,295.1)$ & 202.9 & $(112.9,333.6)$ \\
\hline
\end{tabular}


Table 2: Dietary intake frequency for specifics food group and diet index scores among 208 children living in Mexico City, $2003-2005$

\begin{tabular}{|c|c|c|}
\hline Characteristics & Asthmatic $(n=158)$ & Non-asthmatic $(n=50)$ \\
\hline \multicolumn{3}{|l|}{ Fruit or fruit juice (\%) } \\
\hline At least 4 times a month & 4.4 & 1.8 \\
\hline 2-6 times per week & 34.2 & 23.6 \\
\hline More than once per day & 61.4 & 74.6 \\
\hline \multicolumn{3}{|l|}{ Vegetables (\%) } \\
\hline At least 4 times a month & 1.9 & 1.8 \\
\hline 2-6 times per week & 28.3 & 27.3 \\
\hline More than once per day & 69.8 & 70.9 \\
\hline \multicolumn{3}{|l|}{ Cereals or grains (\%) } \\
\hline At least 4 times a month & 0.6 & 0.0 \\
\hline 2-6 times per week & 21.4 & 20.0 \\
\hline More than once per day & 78.0 & 80.0 \\
\hline \multicolumn{3}{|l|}{ Legumes (\%) } \\
\hline At least 4 times a month & 28.9 & 38.2 \\
\hline 2-6 times per week & 50.9 & 50.9 \\
\hline More than once per day & 20.1 & 10.9 \\
\hline \multicolumn{3}{|l|}{ Dairy products (\%) } \\
\hline At least 4 times a month & 1.3 & 0.0 \\
\hline 2-6 times per week & 8.8 & 12.7 \\
\hline More than once per day & 89.9 & 87.3 \\
\hline \multicolumn{3}{|l|}{ Meat } \\
\hline At least 4 times a month (\%) & 6.9 & 10.9 \\
\hline 2-6 times per week $(\%)$ & 76.1 & 76.4 \\
\hline More than once per day (\%) & 17.0 & 12.7 \\
\hline \multicolumn{3}{|l|}{ Fish (\%) } \\
\hline At least 4 times a month & 76.7 & 74.6 \\
\hline 2-6 times per week & 22.6 & 23.6 \\
\hline More than once per day & 0.6 & 1.8 \\
\hline \multicolumn{3}{|l|}{ Junk food (\%) } \\
\hline At least 4 times a month & 0.6 & 1.8 \\
\hline 2-6 times per week & 34.6 & 21.8 \\
\hline More than once per day & 64.8 & 76.4 \\
\hline \multicolumn{3}{|l|}{ Calories, kcal } \\
\hline$(\operatorname{median}(\mathrm{Q} 25, \mathrm{Q} 75))^{\S}$ & $1797.4(1594.9,2194.4)$ & $1795.2(1569.6,2311.9)$ \\
\hline Vitamins (\%) & 54.4 & 56.4 \\
\hline \multicolumn{3}{|l|}{ Fruit and vegetable index (\%) } \\
\hline 0 & 14.4 & 14.5 \\
\hline I & 33.1 & 25.4 \\
\hline 2 & 36.2 & 43.6 \\
\hline 3 & 16.2 & 16.4 \\
\hline \multicolumn{3}{|l|}{ Mediterranean diet index (\%) } \\
\hline 1 & 37.5 & 41.8 \\
\hline 2 & 18.1 & 25.4 \\
\hline 3 & 23.7 & 16.4 \\
\hline 4 & 20.6 & 16.4 \\
\hline
\end{tabular}

§Mann-Whitney test [median (Q25, Q75)]

foods per day. Vitamin supplementation (mostly vitamin C) was high in both groups. No difference in diet index (FVI or MDI) scores was observed between the two groups.

\section{Air pollution exposure data}

The 8-hour moving average $\mathrm{PM}_{2.5}$ ranged from 4.24 to $102.8 \mu \mathrm{g} / \mathrm{m}^{3}$ during the study period, with a mean of 28.9 $\mu \mathrm{g} / \mathrm{m}^{3}$. It exceeded $30 \mu \mathrm{g} / \mathrm{m}^{3}$ on $52 \%$ of the days. The 8 hour moving average of $\mathrm{NO}_{2}$ ranged from 14.9 to 77.6 $\mathrm{ppb}$, with a mean of $37.4 \mathrm{ppb}$. The 8-hour moving average of $\mathrm{O}_{3}$ ranged from 4.9 to $86.3 \mathrm{ppb}$, with a mean of 31.6 ppb (Table 2). The correlation between $\mathrm{PM}_{2.5}$ and $\mathrm{O}_{3}$ was $\mathrm{r}=0.46(\mathrm{p}=0.000)$. The correlations between $\mathrm{O}_{3}$ and $\mathrm{NO}_{2}$ and $\mathrm{NO}_{2}$ and $\mathrm{PM}_{2.5}$ were $\mathrm{r}=0.28(\mathrm{p}=0.000)$ and $\mathrm{r}=$ $0.61(\mathrm{p}=0.000)$, respectively. Local measurements conducted at the children's schools were correlated with concentrations at the central monitoring stations $(\mathrm{r}=0.77$ for $\mathrm{PM}_{2.5}, \mathrm{r}=0.21$ for $\mathrm{NO}_{2}$ and $\mathrm{r}=0.60$ for $\mathrm{O}_{3}$ ). Mean local measurements were $26.3 \mu \mathrm{g} / \mathrm{m}^{3}$ (standard deviation (SD) 
$=12.5)$ for $\mathrm{PM}_{2.5}, 35.05 \mathrm{ppb}(\mathrm{SD}=12.6)$ for $\mathrm{NO}_{2}$ and 26.9 $\mathrm{ppb}(\mathrm{SD}=9.5)$ for $\mathrm{O}_{3}$.

\section{Association of FVI with lung function and IL-8}

The associations between FVI and main outcomes for the asthmatic and nonasthmatic children are shown in Table 3. After accounting for air pollutants (ozone and $\mathrm{PM}_{2.5}$ ) and confounding factors, FVI was significantly related to lower IL-8 and positively related to lung function. For each 1-unit increase in FVI there was a significant decrease in IL-8. We calculate that children in the highest intake level of the FVI index (4) had 8\% lower IL8 than children with the lowest intake. FVI was not significantly related to exhaled NO but we observed a positive association with exhaled breath $\mathrm{PH}$, although non-significant.

FVI was also positively related to forced expiratory volume in one second $\left(\mathrm{FEV}_{1}\right)$ and forced vital capacity (FVC). The effect was marginally significant for FVC. A 1-point increase in FVI was associated with a $105 \mathrm{ml}$ (nearly 5\%) increase in FVC.

When FVI was analyzed as a categorical variable, we observed a significant decreasing trend in IL-8 levels with increasing categories of FVI $(\mathrm{p}=0.001)$ but no clear trend was observed for lung function (Figure 1).

We observed a significant positive interaction between ozone level and FVI for both $\mathrm{FEV}_{1}(\mathrm{p}=0.023)$ and FVC ( $\mathrm{p}$ $=0.008$ ) suggesting that the protective effect of FVI increased with higher ozone levels (Figure 2). When data were stratified by low ( $\leq 25 \mathrm{ppb}$, max 8 -h moving average) and high ( $\geq 38 \mathrm{ppb}$, max 8-h moving average) ozone levels, we observed that the positive effect of FVI was significantly larger when exposure to ozone was in the highest quartile. (Table 4)

Among non-asthmatic children, FVI was inversely related to IL-8 but this association was not significant. FVI was significantly related to an increase of exhaled NO. No association with lung functions was observed.

\section{Association of MDI with IL-8 and lung functions}

The associations between MDI and main outcomes for the asthmatic children are shown in Table 3. After accounting for air pollutants $\left(\mathrm{O}_{3}, \mathrm{PM}_{2.5}\right)$ and confounding factors, including use of vitamin supplementation, MDI was not related to IL-8 or to exhaled NO or exhaled breath PH. However, it was significantly related to $\mathrm{FEV}_{1}$ and to FVC.

Table 3: Association of inflammatory markers and lung function in school children living in Mexico City with exposure to Fruit and vegetable index and Mediterranean diet index, 2003-2005

\begin{tabular}{|c|c|c|c|c|c|c|}
\hline \multirow[b]{2}{*}{ Models } & \multicolumn{3}{|c|}{ Fruit and vegetable index } & \multicolumn{3}{|c|}{ Mediterranean diet index } \\
\hline & Coefficient* (SE) & $P$ value & P value \& & Coefficient* (SE) & $P$ value & P value \& \\
\hline & \multicolumn{6}{|c|}{ Asthmatic } \\
\hline \multicolumn{7}{|c|}{ Inflammatory markers $\dagger$} \\
\hline In IL-8 & $-0.136(0.055)$ & 0.013 & & $-0.029(0.032)$ & 0.358 & \\
\hline InFeNO & $-0.021(0.086)$ & 0.812 & & $-0.023(0.050)$ & 0.649 & \\
\hline $\mathrm{pH}$ & $0.035(0.026)$ & 0.179 & & $-0.009(0.015)$ & 0.546 & \\
\hline \multicolumn{7}{|l|}{ Lung function $\ddagger$} \\
\hline $\mathrm{FEV}_{1}(\mathrm{~L})$ & $0.074(0.053)$ & 0.165 & 0.023 & $0.058(0.029)$ & 0.045 & \\
\hline FVC (L) & $0.105(0.058)$ & 0.073 & 0.008 & $0.075(0.032)$ & 0.018 & 0.020 \\
\hline \multirow[t]{2}{*}{ FEF25-75 (L) } & $0.048(0.078)$ & 0.539 & & $0.050(0.043)$ & 0.241 & \\
\hline & \multicolumn{6}{|c|}{ Non-asthmatic } \\
\hline \multicolumn{7}{|c|}{ Inflammatory markers $\dagger$} \\
\hline In IL-8 & $-0.133(0.107)$ & 0.214 & & $0.063(0.063)$ & 0.312 & \\
\hline InFeNO & $0.373(0.178)$ & 0.036 & & $0.154(0.115)$ & 0.181 & \\
\hline $\mathrm{pH}$ & $0.04 I(0.052)$ & 0.434 & & $-0.015(0.030)$ & 0.623 & \\
\hline \multicolumn{7}{|l|}{ Lung function $\ddagger$} \\
\hline $\mathrm{FEV}_{1}(\mathrm{~L})$ & $-0.030(0.074)$ & 0.689 & & $-0.016(0.047)$ & 0.730 & \\
\hline FVC (L) & $0.005(0.08 I)$ & 0.952 & & $-0.025(0.052)$ & 0.622 & \\
\hline FEF25-75 (L) & $-0.131(0.129)$ & 0.309 & & $0.047(0.080)$ & 0.557 & \\
\hline
\end{tabular}

* Coefficients correspond to a change in the In IL-8, LnFeno, $\mathrm{pH}$ or lung function for a change in one unit of the FVI or MDI.

t Models for inflammatory markers included 753 inflammatory marker measurements for 119 asthmatic children. Models are adjusted for the following variables: same day exposure: $24-\mathrm{hr}$ average $\mathrm{O}_{3}(\mathrm{pbb}), 24-\mathrm{hr}$ average $\mathrm{PM}_{2.5}\left(\mu \mathrm{g} / \mathrm{m}^{3}\right)$, previous day minimum temperature, gender, body mass index, calories, corticoid use and chronological time.

¥ Models for lung function included 1503 lung function measurements for 158 asthmatic children.

Models are adjusted for the following variables: 5-day accumulated moving average $\mathrm{O}_{3}(\mathrm{ppb}), 5$-day accumulated average $(\mathrm{maximum}) \mathrm{PM}_{2.5}\left(\mu \mathrm{g} / \mathrm{m}^{3}\right)$, previous day minimum temperature, gender, body mass index, calories and chronological time.

${ }_{\mathrm{P}}^{\mathrm{P}}$ value of interaction between ozone and indices (FVI or MDI) 


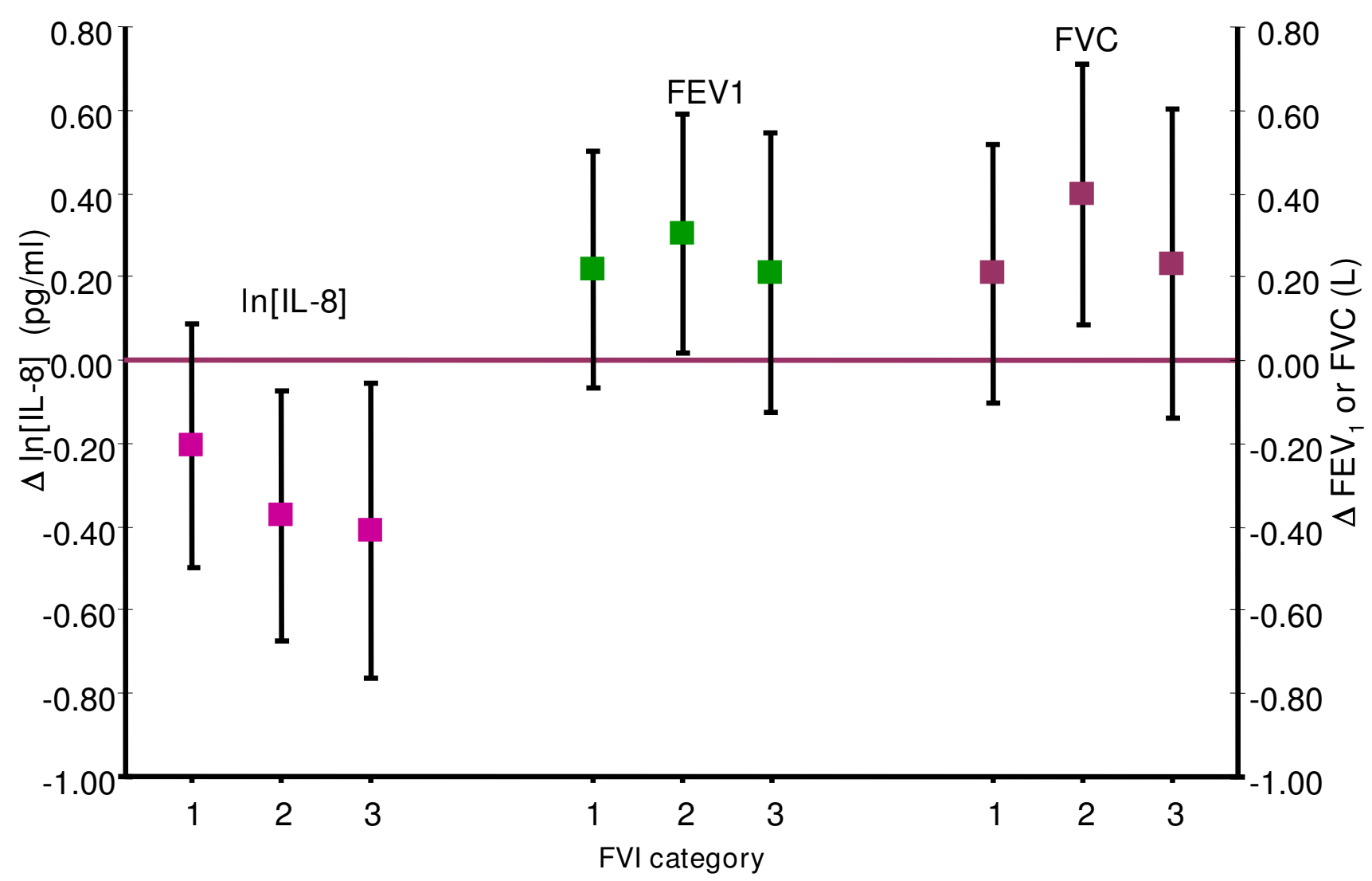

Figure I

Association between In [IL-8] and lung function in asthmatic children living in Mexico City by categories of fruit and vegetable index (FVI) 2003-2005. [In IL-8] model was adjusted for gender, body mass index, calories, 24-hr average $\mathrm{O} 3$ (pbb), previous day minimum temperature, corticoid use and chronological time. Lung function models were adjusted for gender, body mass index, calories, 5-day accumulated moving average $\mathrm{O} 3$ (ppb), previous day minimum temperature and chronological time. Reference category 0.

A 1-point increase in MDI was associated with a $58 \mathrm{ml}$ increase in $\mathrm{FEV}_{1}$ and a $75 \mathrm{ml}$ increase in FVC.

When MDI was used as a categorical variable, we observed that $\mathrm{FEV}_{1}$ and FVC were significantly higher in the highest category when compare to the three lower categories (Figure 3). We calculate that children in the highest intake category of the MDI index (4) had a $15.3 \%$ higher $\mathrm{FEV}_{1}$ and a $16.5 \%$ higher FVC than children with the lowest category.

We observed a significant positive interaction between ozone level and MDI for FVC $(\mathrm{p}=0.02)$ suggesting as for FVI, that the protective effect of MDI increased with increasing levels of ozone. When data were stratified by low ( $\leq 25 \mathrm{ppb}$, max 8-h moving average) and high ozone ( $\geq 38 \mathrm{ppb}$, max 8-h moving average) levels, we observed that the positive effect of MDI on FVC was significantly larger when exposure to ozone was in the highest quartile (Table 4).

Among non-asthmatic children, no significant association was observed between inflammatory markers or lung functions and MDI.

\section{Discussion}

In this prospective cohort study, we observed that a higher intake of fruits and vegetables and close adherence to the MDI had a protective effect on the lung health of asthmatic children. This was observed over the range of 5-22 pulmonary function tests and repeated measurements of IL- 8 in nasal lavage. We found a significant interaction between FVI and MDI and ozone exposure on IL- 8 and lung functions, suggesting that high intake of fruits and vegetables and close adherence to the Mediterranean diet could modulate the adverse effect of $\mathrm{O}_{3}$. 

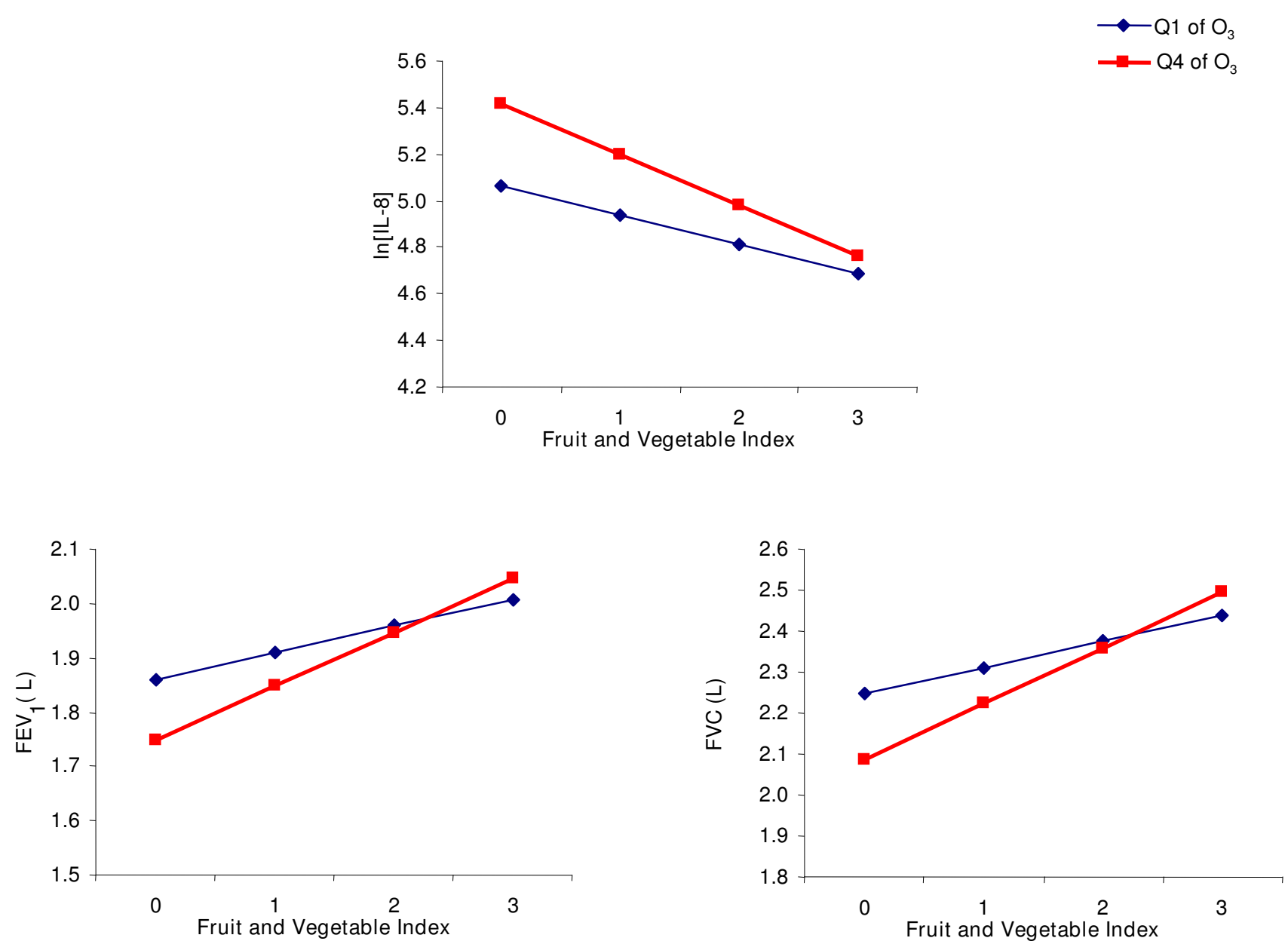

\section{Figure 2}

Interaction between fruits and vegetables index and ozone levels (QI-Q4) for IL8, FEV , and FVC. QI $=\leq 25 \mathrm{ppb}$, max 8-h moving average Q4 = $\geq 38 \mathrm{ppb}$, max 8-h moving average.

Cross-sectional studies have shown that vitamin $\mathrm{C}$ and fruit intake are related to better lung function in adults $[9,26]$. Only one study has reported a similar effect in children [10]. Several studies have also suggested that specific foods might have an impact on asthma and allergies. Vegetables $[9,27,28]$, fruits $[9,27-29]$, dairy products $[9,28,30,31]$ and fish $[9,29,32,33]$ have been associated with reduced asthma risk in children, whereas fast food [34] and dietary fats [31] have been associated with an increased risk. Because foods can interact with one another, it has been suggested that dietary patterns derived from cluster or factor analysis [35] or the use of diet scores [35] are a useful approach for characterizing the diet of individuals and providing nutritional recommendations. Three recent studies have shown a positive impact of adherence to the Mediterranean diet on rhinitis [12] and asthma [13] in children. However, they were subject to bias as they relied on respiratory symptoms reported by parents, with no objective measurement of lung function or inflammatory response. In addition, none of these studies took into account exposure to ambient air pollution--a strong risk factor for respiratory health [36]. The present study, on the other hand, is a prospective study that evaluates the effect of dietary intake of fruits and vegetables and close adherence to the Mediterranean diet on inflammatory response and lung function among asthmatic and non-asthmatic children, taking exposure to air pollutants into account.

We used two types of indices, a fruit and vegetable index and a Mediterranean diet index. Our models were adjusted for total caloric intake as well as for potential confounding factors including gender, body mass index and the use of corticosteroids. While we observed an adverse effect of $\mathrm{O}_{3}$ and $\mathrm{PM}_{2.5}$ on inflammatory response and lung function as reported previously [7], the diet indi- 
Table 4: Association of inflammatory markers and lung function with exposure to Fruit and vegetable index and Mediterranean diet index stratified by the highest and lowest concentrations of ozone in school children living in Mexico City, 2003-2005

\begin{tabular}{|c|c|c|c|c|}
\hline & \multicolumn{2}{|c|}{ First quartile of $\mathrm{O}_{3}(\mathrm{ppb})$} & \multicolumn{2}{|c|}{ Fourth quartile of $\mathrm{O}_{3}(\mathrm{ppb})$} \\
\hline & Coefficient*(SE) & $P$ value & Coefficient*(SE) & $P$ value \\
\hline \multicolumn{5}{|c|}{ Models with exposure to FVI } \\
\hline Ln IL-8† & $-0.125(0.094)$ & 0.182 & $-0.219(0.084)$ & 0.009 \\
\hline $\mathrm{FEV}_{1} \ddagger(\mathrm{L})$ & $0.049(0.061)$ & 0.415 & $0.099(0.058)$ & 0.089 \\
\hline $\mathrm{FVC} \neq(\mathrm{L})$ & $0.065(0.069)$ & 0.346 & $0.137(0.066)$ & 0.037 \\
\hline \multicolumn{5}{|c|}{ Models with exposure to MDI } \\
\hline Ln IL-8† & $-0.020(0.055)$ & 0.723 & $-0.022(0.048)$ & 0.627 \\
\hline $\mathrm{FEV}_{1} \ddagger(\mathrm{L})$ & $0.048(0.033)$ & 0.149 & $0.05 I(0.032)$ & 0.113 \\
\hline $\mathrm{FVC} \neq(\mathrm{L})$ & $0.048(0.037)$ & 0.203 & $0.081(0.036)$ & 0.023 \\
\hline
\end{tabular}

* Coefficients correspond to a change in the In IL-8 or lung function for a change in one unit of the FVI or MDI.

$\dagger\left[\right.$ In IL-8] model included the following variables: same day exposure: $24-\mathrm{hr}$ average $\mathrm{O}_{3}(\mathrm{pbb})$, gender, body mass index, calories, previous day minimum temperature, corticoid use and chronological time.

$\ddagger$ Models for lung function included the following variables: 5-day accumulated moving average $\mathrm{O}_{3}(\mathrm{ppb})$, gender, body mass index, calories, previous day minimum temperature and chronological time.

ces had a consistently beneficial effect on respiratory morbidity. Further adjustment for outdoor activity or distance to the child's residence to the closest high traffic road did not modify our results. A significant interaction was observed between FVI and ozone levels on IL-8 and lung function and between MDI and ozone levels on lung function.

High fruit and vegetable intake as defined by the FVI score appeared to be effective in reducing inflammation, as indicated by the lower IL-8 level in nasal lavage and in improving lung function. The high vitamin $\mathrm{C}$, carotenoid and flavonoid content of the most frequently consumed fruits and vegetables (see dietary intake) might explain this effect, given the important role of antioxidants in protecting against endogenous and exogenous oxidative damage to the airways [37]. Other biologically active phytochemicals present in fruits and vegetables are also likely to have had a protective effect [26].

After accounting for air pollutants, close adherence to the Mediterranean diet was associated with higher lung function. Children in the highest MDI category had an $\mathrm{FEV}_{1}$ and FVC close to $16 \%$ higher than children in the lowest categories. The Mediterranean diet has been shown to have a high antioxidant capacity [11]. It is rich in hydrosoluble antioxidant vitamins and also in liposoluble vitamins and essential fatty acids such as vitamin $E$ and omega-3 polyunsaturated fatty acid. These play a crucial role in protecting against the oxidant-induced lipoperoxidation of polyunsaturated fatty acids in cell membranes [38] and might also have an important role in modulating pulmonary response to oxidative stress. A relatively high consumption of fish (a source of omega-3 fatty acids), typical of the Mediterranean diet, combined with a low omega- 6 intake from dietary fats is thought to modulate inflammation and immunological function, reducing the levels of proinflammatory mediators, such as tumor necrosis factor-alpha, which have been reported to be higher in asthmatic subjects [39].

An interaction of FVI and MDI and $\mathrm{O}_{3}$ exposure was observed on inflammatory response and lung function, suggesting that a diet rich in antioxidants and highly adherent to the Mediterranean diet could modulate the adverse effect of $\mathrm{O}_{3}$ on the respiratory health of asthmatic children. Ozone is a strong oxidant and high exposure can overwhelm antioxidant defenses and lead to decreased lung functions [7]. These results are in accordance with our recent findings on the modulating effect of vitamin $\mathrm{C}$ and Vitamin E supplementation on the adverse effect of $\mathrm{O}_{3}$ on lung function in asthmatic children [8] and suggest that protection against environmental insult can be achieved by an appropriate diet.

Adherence to the Mediterranean diet was assessed using an adaptation of the index developed by Trichopoulou [23] to evaluate population food habits, based on positive scoring for protective nutrients and negative scoring for detrimental nutrients. The index was modified slightly to fit a child population [40]. One of the advantages of this index is that it takes into account synergic effects or interactions between foods or nutrients [41], overrides correlations between different foods and minimizes error in the intake of specific nutrients, since it reflects the whole dietary pattern rather than specifically interesting nutrients or 


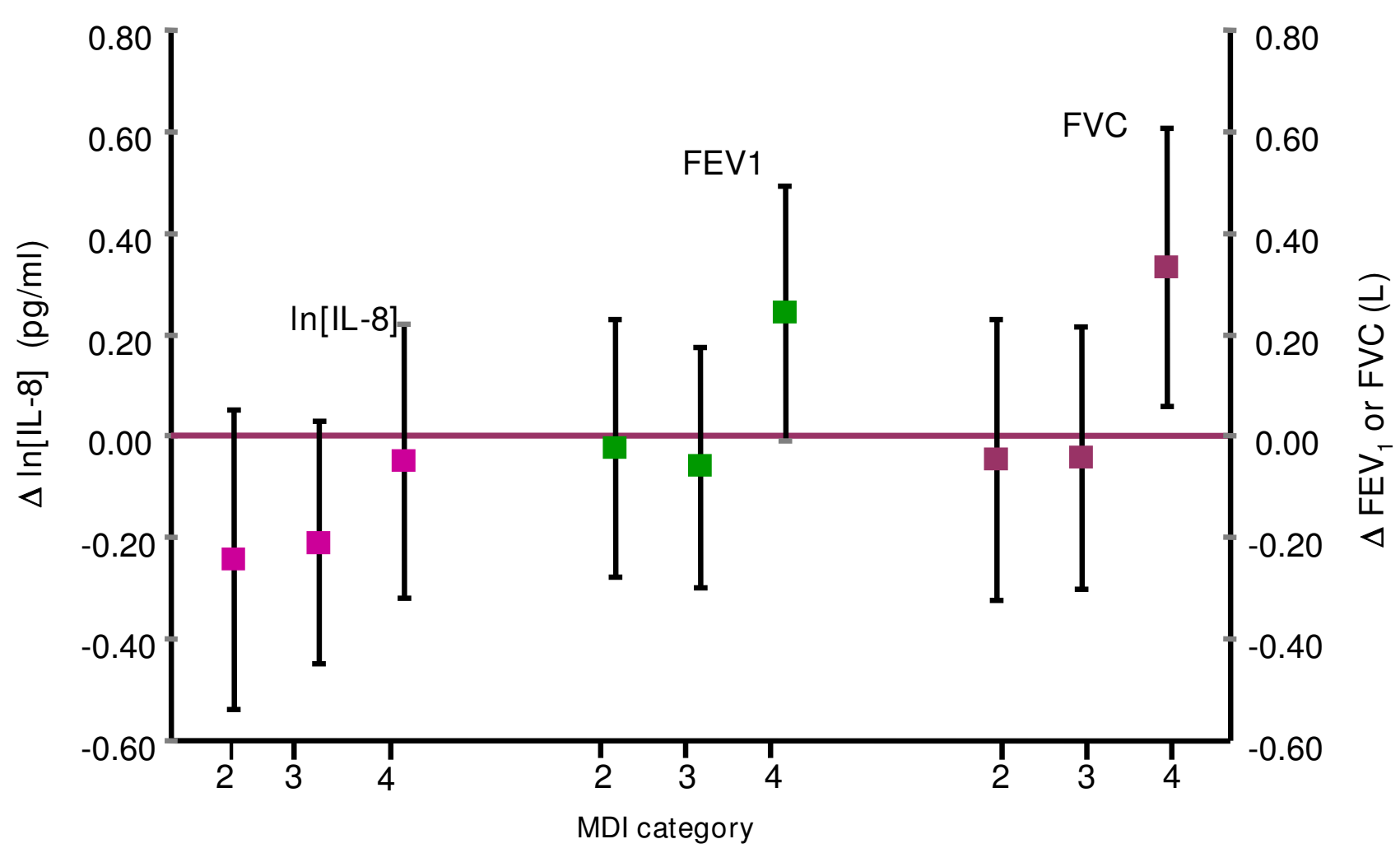

Figure 3

Association between In [IL-8] and lung function in asthmatic children living in Mexico City by categories of Mediterranean diet index (MDI) 2003-2005 [InIL-8] model was adjusted for gender, body mass index, calories, 24-hr average $\mathrm{O} 3$ (pbb), previous day minimum temperature, corticoid use and chronological time. Lung function models were adjusted for gender, body mass index, calories, 5-day accumulated moving average $\mathrm{O} 3$ (ppb), previous day minimum temperature and chronological time. Reference category I.

foods. In addition, use of the score improved statistical power, which is a concern when studying single nutrients or foods that account for small effects [40].

A number of issues need to be addressed in interpreting our results. Dietary intake was based on a food frequency questionnaire and the foods were then classified into 8 food groups to calculate the diet scores. This questionnaire had been validated in the Mexican population and the information on dietary intake was provided by the child's mother. Dietary intake is likely to vary with age among children; however, our study was focusing on acute and subacute effects and the time window covered by the questionnaire therefore appears adequate. While some error in reporting food intake is unavoidable, we believe it is random as both lung function tests and IL-8 measurements are objective outcomes and parents were unaware of the results. In addition, we obtained an average of 7 repeated measurements for lung function and 4 measurements for IL-8 per child, which increased our power, and we further adjusted for air pollution levels. We therefore believe our results provide a reliable estimation of the beneficial effect of diet on lung health in our population of asthmatic and non-asthmatic children.

Levels of IL-8 observed in our study were concordant with that observed in the nasal lavage in other studies [42-44]. We observed that the children with the highest intake (level 4) of FVI had a 13.7\% lower IL-8 concentration than children in the first intake level.

We used repeated lung function measurements and learning curves could affect our

results; asthmatic children are used to performing spirometric tests and this would therefore more likely affect non-asthmatic children. However, excluding the first 2 spirometric tests from our analysis led to similar results.

The non-significant beneficial effect of diet observed among non-asthmatic children could be due to different factors. First, our sample size of non-asthmatic children 
was small because we had difficulties getting healthy children to visit our clinic. This would have influenced our power to detect a significant effect. Also, non-asthmatic children are known to have higher levels of antioxidants in the serum [45] and have less oxidative stress [46] It might therefore be easier to detect a beneficial effect among asthmatic children because of their susceptibility.

\section{Conclusions}

Our findings indicate that a high dietary intake of commonly consumed fruits and vegetables and a close adherence to the Mediterranean diet had a protective effect on airway inflammation and lung function in our population of asthmatic children highly exposed to air pollutants. A "healthy diet" should be promoted to counteract environmental insults in asthmatic children. A stronger modulating effect was observed among asthmatic children exposed to high ozone levels.

\section{List of abbreviations}

FVI: Fruit and vegetable index; MDI: Mediterranean diet index; FVC: Forced vital capacity; $\mathrm{FEV}_{1}$ : Forced Expiratory Volume after 1 second; $\mathrm{PM}_{2.5}$ : Fine particles; $\mathrm{O}_{3}$ : Ozone; GINA: Global Initiative for Asthma; $\mathrm{NO}_{2}$ : Nitrogen dioxide; RAMA: Government at four fixed-site central monitoring.

\section{Competing interests}

The authors declare that they have no competing interests.

\section{Authors' contributions}

IR: Developed the protocol, obtained funding for the project, and directed the data analysis and the writing of the manuscript. AB: participated in the protocol, data collection, standarization and realization of lung testing, interpretation and data analysis and writing of the manuscript. CE: data analysis and interpretation of the data; JT: participated on data collection; LH: participated on data analysis; DD: participated on measurement of IL-8 and $\mathrm{pH}$ and interpretation of the data; JDB: participated in the data collection and interpretation; and BD: participated in standardization of lung testing and data collection.

All authors have read and approved the final manuscript.

\section{Acknowledgements}

The authors thank the school children who took part in the study, the personnel who carried out the field work and Garth Evans for his editorial assistance. The study was supported by Mexican Sciences and Technology Council (CONACYT) Grant No. 389II-M and the Mexican Ministry of Health Grant No. 2002-C0I-7624.

\section{References}

I. Castillejos M, Gold DR, Damokosh AI, Serrano P, Allen G, McDonnell WF, Dockery D, Ruiz Velasco S, Hernández M, Hayes C: Acute effects of ozone on the pulmonary function of exercising schoolchildren from Mexico City. Am J Respir Crit Care Med 1995 , I52:150I-I507.

2. Gauderman WJ, Vora H, McConnell R, Berhane K, Gilliland F, Thomas D, Lurmann F, Avol E, Kunzli N, Jerrett M, et al.: Effect of exposure to traffic on lung development from 10 to 18 years of age: a cohort study. Lancet 2007, 369(956I):57I-577.

3. Rojas-Martinez R, Perez-Padilla R, Olaiz-Fernandez G, MendozaAlvarado L, Moreno-Macias H, Fortoul T, McDonnell W, Loomis D, Romieu I: Lung function growth in children with long-term exposure to air pollutants in Mexico City. Am J Respir Crit Care Med 2007, I76(4):377-384.

4. Heinrich J, Wichmann HE: Traffic related pollutants in Europe and their effect on allergic disease. Curr Opin Allergy Clin Immunol 2004, 4(5):34I-348.

5. Romieu I, Meneses F, Ruiz S, Sienra IJ, Huerta J, White MC, Etzel RA: Effects of air pollution on the respiratory health of asthmatic children living in Mexico City. Am J Respir Critic Care Med 1996, I 54:300-307.

6. Ward DJ, Ayres JG: Particulate air pollution and panel studies in children: a systematic review. Occup Environ Med 2004, 64: 13 .

7. Barraza-Villarreal A, Sunyer J, Hernandez-Cadena L, Escamilla-Nuñez C, Sienra-Monge IJ, Ramirez-Aguilar M, Cortez-Lugo M, Holguin F, Diaz-Sanchez D, Olin AC, et al.: Air Pollution, airway inflammation and lung function in a chort study of Mexico City schoolchildren. Environ Health Perspect 2008, I l 6:832-838.

8. Romieu I, Meneses F, Ramirez M, Ruiz S, Perez Padilla R, Sienra JJ, Gerber M, Grievink L, Dekker R, Walda I, et al.: Antioxidant supplementation and respiratory functions among workers exposed to high levels of ozone. Am J Respir Crit Care Med 1998, I58(I):226-232.

9. Romieu I: Nutrition and lung health. Int J Tuberc Lung Dis 2005, 9(4):362-374.

10. Gilliland FD, Berhane KT, Li YF, Gauderman WJ, McConnell R, Peters $\mathrm{J}$ : Children's lung function and antioxidant vitamin, fruit, juice, and vegetable intake. Am J Epidemiol 2003, I 58:576-584.

II. Pitsavos C, Panagiotakos DB, Tzima N, Chrysohoou C, Economou M, Zampelas A, Stefanadis C: Adherence to the Mediterranean diet is associated with total antioxidant capacity in healthy adults: the ATTICA study. Am J Clin Nutr 2005, 82(3):694-699.

12. Chatzi L, Apostolaki G, Bibakis I, Skypala I, Bibaki-Liakou V, Tzanakis N, Kogevinas M, Cullinan P: Protective effect of fruits, vegetables and the Mediterranean diet on asthma and allergies among children in Crete. Thorax 2007, 62(8):677-683.

13. Garcia-Marcos L, Canflanca IM, Garrido JB, Varela AL, Garcia-Hernandez G, Guillen Grima F, Gonzalez-Diaz C, Carvajal-Urueña I, Arnedo-Pena A, Busquets-Monge RM, et al.: Relationship of asthma and rhinoconjunctivitis with obesity, exercise and Mediterranean diet in Spanish schoolchildren. Thorax 2007, 62:503-508.

14. From the Global Strategy for Asthma Management and Prevention: Global Initiative for Asthma (GINA). 2008 [http://www.ginas thma.org/Guidelineitem.asp?! |=2\&|2=|\&intld=60].

15. American Thoracic Society: Standardization of spirometry. Am J Respir Crit Care Med 1995, I 52: I 107-I I 36.

16. Diaz-Sanchez D, Dotson AR, Takenaka H, Saxon A: Diesel exhaust particles induce local IgE production in vivo and alter the pattern of IgE messenger RNA isoforms. J Clin Invest 1994, 94:1417-1425.

17. American Thoracic Society: Recommendations for standarized procedures for the online and offline measurement of exhaled lower respiratory nitric oxide and nasal nitric oxide in adults and children --- 1999. Am J Respir Crit Care Med 1999, 160:2104-2117.

18. Hunt J: Exhaled breath condensate: an envolving tool for noninvasive evaluation of lung disease. J Allergy Clin Immunol 2002, I 1 0:28-34.

19. Horváth I, Hunt J, Barnes PJ, Alving K, Antczak A, Baraldi E, Becher G, van Beurden W], Corradi M, Dekhuijzen R, et al.: Exhaled breath condensate: methodological recommendations and unresolved questions. Eur Respir J 2005 Sep; 26(3): 523-48 2005, 26:523-548.

20. Hernández-Avila M, Romieu I, Parra S, Hernández-Avila J, Madrigal H, Willett $\mathrm{W}$ : Validity and reproducibility of a food frequency questionnaire to assess dietary intake of women living in Mexico City. Salud Publica Mex 1998, 40(2): I33-I40. 
21. Romieu I, Parra S, Hernández JF, Madrigal H, Willett W, Hernández $M$ : Questionnaire assessment of antioxidants and retinol intakes in Mexican women. Arch Med Res 1999, 30:224-239.

22. Willett WC: Nutritional Epidemiology. Second edition. New York: Oxford University Press; 1998.

23. Trichopoulou A, Costacou T, Bamia C, Trichopoulos D: Adherence to a Mediterranean diet and survival in a Greek population. N Engl J Med 2003, 348:2599-2608.

24. Goulet J, Lamarche B, Nadeau G, Lemieux S: Effect of a nutritional intervention promoting the Mediterranean food pattern on plasma lipids, lipoproteins and body weight in healthy French-Canadian women. Atherosclerosis 2003, 1 70:1 15-124.

25. Hausman J: Specification tests in econometrics. Econometrica 1978, 46:|25|-|27|.

26. Romieu I, Varraso R, Avenel V, Leynaert B, Kauffmann F, ClavelChapelon F: Fruit and vegetable intakes and asthma in the E3N study. Thorax 2006, 6 I (3):209-2I 5.

27. Cook DG, Carey IM, Whincup PH, Papacosta O, Chirico S, Bruckdorfer KR, Walker M: Effect of fresh fruit consumption on lung function and wheeze in children. Thorax 1997, 52(7):628-633.

28. Farchi S, Forastiere F, Agabiti N, Corbo G, Pistelli R, Fortes C, Dell'Orco V, Perucci CA: Dietary factors associated with wheezing and allergic rhinitis in children. Eur Respir J 2003, 22(5):772-780.

29. Antova T, Pattenden S, Nikiforov B, Leonardi GS, Boeva B, Fletcher T, Rudnai P, Slachtova H, Tabak C, Zlotkowska R, et al.: Nutrition and respiratory health in children in six Central and Eastern European countries. Thorax 2003, 58(3):23I-236.

30. Riedler J, Braun-Fahrländer C, Eder W, Schreuer M, Waser M, Maisch S, Carr D, Schierl R, Nowak D, von Mutius E, et al.: Exposure to farming in early life and development of asthma and allergy: a cross-sectional survey. Lancet 200 I, 358(9288): I I 29-I I 33.

31. Wijga AH, Smit HA, Kerkhof M, de Jongste JC, Gerritsen J, Neijens HJ, Boshuizen HC, Brunekreef B, PIAMA: Association of consumption of products containing milk fat with reduced asthma risk in pre-school children: the PIAMA birth cohort study. Thorax 2003, 58(7):567-572.

32. Hodge L, Salome CM, Peat JK, Haby MM, Xuan W, Woolcock AJ: Consumption of oily fish and childhood asthma risk. Med J Aust 1996, I64:|37-140.

33. Tabak C, Wijga AH, de Meer G, Janssen NA, Brunekreef B, Smit HA: Diet and asthma in Dutch school children (ISAAC-2). Thorax 2006, 6 I ( I 2): 1048-1053.

34. Wickens K, Barry D, Friezema A, Rhodius R, Bone N, Purdie G, Crane J: Fast foods - are they a risk factor for asthma? Allergy 2005, 60( ( 2): | 537-|54|.

35. Hu FB: Dietary pattern analysis: a new direction in nutritional epidemiology. Curr Opin Lipidol 2002, I3:3-9.

36. Sandström T, Brunekreef B: Traffic-related pollution and lung development in children. Lancet 2007, 369:353-357.

37. Bowler RP, Crapo JD: Oxidative stress in airways: is there a role for extracellular superoxide dismutase? Am J Respir Crit Care Med 2002, 1 66:38-43.

38. Fairfield KM, Fletcher RH: Vitamins for chronic disease prevention in adults. JAMA 2002, 287:31 I6-3126.

39. Broide DH, Lotz M, Cuomo AJ, Coburn DA, Federman EC, Wasserman SI: Cytokines in symptomatic asthma airways. J Allergy Clin Immunol 1992, 89:958-967.

40. de Batlle J, Garcia-Aymericha J, Barraza-Villarreal A, Antó JM, Romieu I: Mediterranean diet reduces risk of asthma and allergic rhinitis in Mexican children. Allergy 2008, 63:1310-1316.

41. Kant AK: Dietary patterns and health outcomes. J Am Diet Assoc 2004, I 04(4):615-635.

42. Dosman JA, Fukushima Y, Senthilselvan A, Kirychuk SP, Lawson JA, Pahwa P, Cormier Y, Hurst T, Barber EM, Rhodes CS: Respiratory response to endotoxin and dust predicts evidence of inflammatory response in volunteers in a swine barn. Am J Ind Med 2006, 49:76I-766.

43. Widegren H, Erjefält J, Korsgren M, Andersson M, Greiff L: Effects of intranasal TNFalpha on granulocyte recruitment and activity in healthy subjects and patients with allergic rhinitis. Respir Res 2008, 9:15.

44. Benson M, Strannegård IL, Wennergren G, Strannegård O: Inter leukin-5 and interleukin-8 in relation to eosinophils and neutrophils in nasal fluids from school children with seasonal allergic rhinitis. Pediatr Allergy Immunol 1999, I 0: I78- I85.
45. Zeyrek D, Cakmak A, Atas A, Kocyigit A, Erel O: DNA damage in children with asthma bronchiale and its association with oxidative and antioxidative measurements. Pediatr Allergy Immunol 2009, 20(4):370-376.

46. Liao MF, Chen CC, Hsu MH: Evaluation of the serum antioxidant status in asthmatic children. Acta Paediatr Taiwan 2004, 45:213-217.
Publish with Biomed Central and every scientist can read your work free of charge

"BioMed Central will be the most significant development for disseminating the results of biomedical research in our lifetime. "

Sir Paul Nurse, Cancer Research UK

Your research papers will be:

- available free of charge to the entire biomedical community

- peer reviewed and published immediately upon acceptance

- cited in PubMed and archived on PubMed Central

- yours - you keep the copyright

Submit your manuscript here:

http://www.biomedcentral.com/info/publishing_adv.asp
BiolMedcentral 